\title{
EDITORIAL DOSSIÊ CIDADE E MEMÓRIA
}

Viviane Gomes de Ceballos Universidade Federal de Campina Grande vgceballos@gmail.com

Andar pela cidade, perceber o traçado de suas ruas, estudar os estilos arquitetônicos de seus prédios ou o seu centro histórico nos abre a possibilidade de ver e viver a cidade em perspectivas plurais, mas que deixam ainda obscuras tantas outras possibilidades de leitura do espaço citadino. Neste número a Urbana abre espaço para discussões que nascem da preocupação em entender a cidade como um espaço que ganha contornos e formas ao sabor das memórias que a constituem. A cidade torna-se plástica, moldável, maleável às falas de seus tantos habitantes, visitantes, urbanistas, cronistas, enfim, de todos aqueles que com ela vivem ou viveram algum tipo de relação - seja de identificação ou de estranhamento.

Pensar essas narrativas ditas e escritas em diversos momentos da vida dos habitantes da cidade consiste em um desafio instigante ao pesquisador do urbano. A todo instante nos deparamos com a defesa de alguns historiadores de que a nossa narrativa deve ser marcada pela objetividade e pelo caráter de cientificidade que lhe é inerente. Parece-me bastante propositivo pensar na construção da história a partir dessa mescla entre os "desejos" do historiador e seu compromisso com aquilo que suas fontes o permitem dizer. Reconhecer a impossibilidade de atingir uma verdade "absoluta" é reconhecer a pluralidade inerente à própria história, mesmo sem perder de vista que essa pluralidade dependerá dos vestígios, dos indícios que elegemos como significativos para tal pesquisa.

A saber, como nos ensina Bloch, a história carece de uma dose imensa de escolha pessoal, e essas escolhas são fruto do lugar em que se encontra o historiador. Lidar com a impossibilidade da construção de uma narrativa objetiva e total já era uma preocupação apontada por Lucien Febvre ao afirmar que "não adianta, você nunca poderá ver tudo, haverá sempre fontes que the escapam" (apud DUBY, 1989, p. 37). Por isso, usando a metáfora criada por Duby, o passado 
se apresenta como um "tecido amarrotado, coçado, rasgado"; ao historiador jamais será possível reconstitui-lo em sua totalidade, ou sequer conhecer a extensão daquilo que está perdido. As lacunas, assim como a subjetividade, são partes inerentes ao nosso ofício. Ao historiador fica o desafio de lidar com os limites, com aquilo que o lugar de produção da história Ihe permite ou Ihe proíbe dizer, uma vez que

a história se define inteira por uma relação da linguagem com o corpo (social) e, portanto, também pela sua relação com os limites que o corpo impõe, seja à maneira do lugar particular de onde se fala, seja à maneira do objeto outro (passado, morto) do qual se fala (CERTEAU, 2008, p. 77).

Somente quando consideramos a importância do lugar social ${ }^{1}$ no processo de construção da história é que perceberemos sua própria historicidade. O nãolugar impede a história de ser história e o historiador de construir o seu corpus documental. O historiador - que tem o tempo como material de análise ou como objeto específico - trabalha

de acordo com os seus métodos, os objetos físicos (papéis, pedras, imagens, sons, etc.) que distinguem, no continuum do percebido, a organização de uma sociedade e o sistema de pertinências próprias de uma 'ciência'. Trabalha sobre um material para transforma-lo em história. (CERTEAU, 2008, p. 79)

A produção da narrativa histórica acaba voltando-se a uma postura de respeito aos interlocutores com os quais lidamos na pesquisa. Devemos ter com eles uma postura de respeito, postura expressa na necessidade de inserir cada um deles no seu lugar de autor, levando em consideração o seu arcabouço conceitual que informa e institui as suas interpretações acerca do mundo. Estaríamos, assim, diante de "um quadro vivo resultante da recusa em bani-los de antemão ou de cristalizá-los como paradigmas; uma atitude respeitosa em relação às posições assumidas, ainda quando delas discordamos." (BRESCIANI, 2009, p. 183) Assim, essa postura respeitosa deve ser estendida tanto aos autores com que dialogamos

\footnotetext{
${ }^{1}$ Lugar social entendido a partir da proposta de Michel de Certeau quando afirma que este é caracterizado pelo lugar social, político, econômico, institucional, ideológico, etc. ocupado pelo historiador no momento de elaboração de seu texto. (CERTEAU, 2008)
} 
quanto, e talvez sobretudo, aos nossos colaboradores - que se dispuseram a narrar suas experiências, ou às narrativas memorialísticas e tudo o que constitui a(s) memória(s) citadina(s).

Compartilhando da ideia apresentada por Jeanne Marie Gagnebin no prefácio ao volume I das "Obras Escolhidas de Walter Benjamin - Magia e Técnica, Arte e Política", em que afirma que, para Benjamin, "a reconstrução da experiência deveria ser acompanhada de uma nova forma de narratividade" (GAGNEBIN, 1994, p. 09) este número da Revista Urbana apresenta-se como espaço para discussões sobre a relação existente entre experiência, narratividade e memória como possibilidade de entendimento das trajetórias trilhadas pelos diferentes indivíduos que compõem uma coletividade e a forma como se apropriam das imagens que parecem caracterizar essa mesma coletividade a partir de duas questões principais: a relação entre a memória e a história; e o entendimento do espaço citadino a partir das memórias que o constituem.

Pensar a relação entre memória e história é deparar-se com uma complexidade de entendimentos e de procedimentos que norteiam o trabalho do historiador para quem, assim como Proust, pensa que a

vida é vagabunda, nossa memória é sedentária, ou seja, à descontinuidade das experiências ao longo do tempo, a memória, igualmente descontínua, revela a possibilidade de algo único. A memória, portanto, constrói o real, muito mais do que o resgata (SEIXAS, 2001, p. 39).

É, portanto, entender a memória como presentificação do passado, (re)elaboração, (re)construção de uma experiência vivida. A memória não traz de volta a experiência vivida, mas constrói uma elaboração, uma digressão sobre essa mesma experiência. O falar, o narrar - embora impossibilitado pela vida moderna, como afirma Benjamin - constrói uma unicidade e uma lógica cadencial para os acontecimentos que não existia no momento em que a experiência se deu. Esse "algo único" de que nos fala Jacy Seixas (2001), é essa possibilidade que a memória tem de permitir uma organização de fatos descontínuos, uma ordenação mesma da vida em torno de expectativas e de questões presentes - é o dar forma à memória pessoal, mencionado por Monique Augras. 
O rememorar é, então, entendido como um ato político e intencional de formulação de uma imagem sobre o passado e sobre a experiência vivida, seja ela entendida na individualidade ou mesmo na coletividade. Um ato que não prescinde da marca do seu narrador, do seu enunciador. A narrativa traz em si "impressas as marcas do narrador como os vestígios das mãos do oleiro no vaso da argila." (BENJAMIN, 1989, p. 107) Essa impressão remete, inclusive, a uma noção de tempo que varia de acordo com a situação vivenciada. Para Bergson, a mesma durée pode ser vivenciada de formas distintas - pode parecer interminável se vazia de significado, ou ainda, parecer um momento fugaz se plena de intensidade psicológica. (BENJAMIN, 1989)

Aqueles que são incitados a lembrar dão à sua memória contornos próprios dessa vivência, uma vez que "lembrar não é reviver, mas re-fazer. É reflexão, compreensão do agora a partir do outrora; é sentimento, reaparição do feito e do ido, não sua mera repetição". (BOSI, 1994, p. 20) Pensar na estreita relação entre passado e presente quando se fala de memória é pensar também em como se constitui a sua dimensão temporal. Passado e presente estabelecem uma relação de reciprocidade na medida em que constituem partes integrantes do processo do rememorar. Aquilo que Bergson chama de presentificação da durée seria o processo de apropriação mesmo das lembranças e transformação dessa experiência em memória voluntária. Benjamin chega a afirmar que esse processo de presentificação seria uma forma, também, de amortização do choque das experiências vividas pela uniformização dessas experiências em uma narrativa coerente, mas que "não pode contudo evitar que nela persistam a existência de fragmentos desiguais e privilegiados." (BENJAMIN, 1989, p. 136) Por mais coesão que se tente dar a rememoração de um fato esse processo implicará sempre em imperfeições, em lacunas que são inerentes a qualquer tipo de narratividade.

Este caráter lacunar e imperfeito da memória é, para Todorov, inerente a ela. Não há oposição entre memória e esquecimento - eles são partes de um mesmo processo.

O uso da memória como instrumento de elaboração do conhecimento histórico pressupõe mais do que conceder ao outro (ao colaborador) o direito à lembrança; é mais do que isso, Todorov lança o desafio de conceder ao nosso interlocutor o direito ao esquecimento. O processo de elaboração de uma imagem de si no presente, implica que "para comenzar a hablar, hay que poner o pasado entre parêntesis" (TODOROV, 2000, p. 27), ou seja, repensar ações, vivências, 
decisões e dar a elas os contornos que o momento presente the exige, ou the permite fazer. Até mesmo considerar a impossibilidade de fazê-lo, o direito de manter no esquecimento fatos imagens que não queremos mais relacionar à nossa vida, à nossa imagem. Essa complexa dinâmica, própria da memória, se amplia quando, ao ser instigado a lembrar o indivíduo se vê diante de um processo que vai conceder ao outro (geralmente um desconhecido) as interpretações sobre sua própria experiência. Abrir mão do lugar de construtor de si não é processo fácil, portanto, implica ao depoente a construção de uma imagem bem consolidada de si e que não deixe muita margem à interpretações "errôneas" sobre ele ou sua atuação num determinado momento do passado.

Bastante profícua é a ideia dessa complexidade ${ }^{2}$ de que fala Todorov e que nos instiga a pensar os meandros da relação que se constrói entre a memória e a história. A história se coloca fora dos grupos que viveram aqueles acontecimentos e cria ligações artificiais entre eles. Há uma multiplicidade de tempos tantos quantos são os grupos que compõem a sociedade. Mas nenhuma dessas consciências coletivas de tempo se impõe a todos os outros grupos. Ou seja, não há como falar em uma memória universal, como pretende a história, pois, como afirma Benjamin ao discutir Proust

um acontecimento vivido é finito, ou pelo menos encerrado na esfera do vivido, ao passo que o acontecimento lembrado é sem limites, porque é apenas uma chave para tudo o que veio antes e depois." (BENJAMIN, 1994, p. 37)

O trabalho com a memória e com a história oral implica considerar, além das subjetividades, as inúmeras temporalidades que as compõem: da experiência vivida, da experiência rememorada, do presente em que rememora, e do presente do historiador quando se dedica a estudar essa rememoração.

Ao colaborador cabe a construção e a tessitura da narrativa da forma que achar mais adequada para os contornos que quer dar à sua memória. Diferentemente dos historiadores, o colaborador não tem uma preocupação em entender ou mesmo explicar os fatos que narra ou as conexões que estabelece entre eles - essa é uma característica marcante da narrativa para Benjamin. (1989,

\footnotetext{
2 Ver também: RICOEUR (2007); SEIXAS (2001); NORA (1993); LE GOFF (2003); BERGSON (1999); HALBWACHS (1990); BOSI (1994).
} 
p. 203) A riqueza da oralidade, para o historiador, está em identificar esses contornos e a importância deles para a elaboração da narrativa do colaborador. Assim, os meus interlocutores ao falarem de Brasília e da relação que estabelecem com essa cidade me concedem não apenas o conteúdo mesmo de sua narrativa memorialística, mas os silêncios e as inquietudes que vivenciam no exercício de lembrar.

Assim, pensar a cidade a partir da fala de seus moradores, das memórias de seus edificadores, gestores, enfim, daqueles que a constituem, implica refletir sobre essas várias temporalidades e subjetividades que estão envolvidas no processo de historiar. A experiência de hoje lembrar sobre um fato passado, ocorrerá mediante o estímulo de questões colocadas pelo historiador/entrevistador, de fotografias apresentadas ou mesmo de um passeio pelas ruas da cidade, no entanto, essa será uma memória perpassada pelos limites que o historiador acaba colocando para o seu colaborador ${ }^{3}$ no momento da entrevista/pesquisa.

Entendida como um espaço plural e complexo a cidade ganha contornos a partir dos diferentes discursos que incidem sobre ela - de urbanistas, de jornalistas, de cronistas, de memorialistas e de habitantes que acabam atribuindo significados à cidade e aos usos que são feitos dela a partir de seu lugar de atuação. Neste número a Revista Urbana apresenta as discussões e perspectivas traçadas por diferentes estudiosos sobre o espaço citadino e as relações com seus habitantes.

\section{Referências}

BENJAMIN, Walter. "Sobre alguns temas em Baudelaire". In: Obras escolhidas III - Charles Baudelaire um lírico no auge do capitalismo. São Paulo: Brasiliense, 1989, pp. 103-150.

BENJAMIN, Walter. Obras escolhidas I - Magia e técnica, arte e política: ensaios sobre literatura e história da cultura. 7 ed. São Paulo: Brasiliense, 1994.

\footnotetext{
3 Pesquisadores do NEHO/USP utilizam a nomenclatura de colaborador para referirem-se aos entrevistados, por entenderem que estes não apenas narram as suas experiências individuais, mas contribuem para a elaboração e consolidação de um saber que depende da forma como eles trabalham essa memória.
} 
BOSI, Ecléa. Memória e Sociedade: lembrança de velhos. 3 ed. São Paulo, Companhia das Letras, 1994.

BRESCIANI, Maria Stella Martins. Um possível diálogo entre (e com) os intérpretes do Brasil. In: SOIHET, Rachel (org.). Mitos, projetos e práticas políticas: memória e historiografia. Rio de Janeiro: Civilização Brasileira, 2009, pp. 161-184.

CERTEAU, Michel de. A Operação Historiográfica. In: A Escrita da História. 2 ed. Rio de Janeiro, Forense Universitária, 2008, pp. 65-122.

DUBY, Georges; LARDREAU, Guy. Diálogos sobre a nova história. Lisboa: Publicações Dom Quixote, 1989.

GAGNEBIN, Jeanne Marie. "Prefácio: Walter Benjamin ou a história aberta". In: BENJAMIN, Walter. Obras escolhidas I - Magia e técnica, arte e política: ensaios sobre literatura e história da cultura. 7 ed. São Paulo: Brasiliense, 1994, pp. 7-20.

SEIXAS, Jacy Alves de. "Percursos de memórias em terras de história: problemáticas autais". In: BRESCIANI, M. S. M. \& NAXARA, M. (orgs.) Memória e (res)sentimento: indagações sobre uma questão sensível. Campinas: Editora da Unicamp, 2001.

TODOROV, Tzvetán. Los abusos de la memoria. Buenos Aires: Paidós, 2000. 